Revista Brasileira de Agricultura Irrigada v.10, no .5, p. 990 - 998, 2016

ISSN 1982-7679 (On-line)

Fortaleza, CE, INOVAGRI - http://www.inovagri.org.br

DOI: $10.7127 /$ rbai.v10n500495

Protocolo 495.16 - 29/09/2016 Aprovado em 13/10/2016

\title{
EFEITO DA APLICAÇÃO DE UREIA E DE CLORETO DE POTÁSSIO POR FERTIRRIGAÇÃO NA VAZÃO DOS EMISSORES E EM PARÂMETROS QUÍMICOS DO SOLO
}

\author{
Dionei Lima Santos ${ }^{1}$, Eugenio Ferreira Coelho ${ }^{2}$, Lucas dos Santos Batista ${ }^{3}$, Damiana Lima \\ Barros $^{4}$, Raimundo Rodrigues Gomes Filho ${ }^{5}$, Clayton Moura de Carvalho ${ }^{6}$
}

\begin{abstract}
RESUMO
A fertirrigação vem sendo incorporada aos sistemas de produção de diversas frutíferas no Brasil, resultando em maior demanda de conhecimento dessa tecnologia em relação o seu efeito na dinâmica de solutos no solo. Diante desse contexto, esse trabalho teve como objetivo avaliar os efeitos do uso dos fertilizantes ureia e cloreto de potássio via água de irrigação na emissão de água pelos emissores e nos atributos químicos do solo ( $\mathrm{pH}$ e condutividade elétrica) na cultura do mamoeiro por gotejamento. As avaliações foram conduzidas dentro de um experimento delineado em blocos ao acaso, onde os tratamentos constituíram-se de cinco doses de $\mathrm{N}$ e cinco doses de $\mathrm{K}_{2} \mathrm{O}$, perfazendo 10 tratamentos. Foram instalados extratores de solução no solo às distâncias horizontais de $0,03 \mathrm{~m}, 0,20 \mathrm{~m}, 0,40 \mathrm{~m}$ e $0,60 \mathrm{~m}$ do gotejador, às profundidades de $0,20 \mathrm{~m}, 0,40 \mathrm{~m}, 0,60 \mathrm{~m}$ e $0,80 \mathrm{~m}$ próximo da planta, de forma a simular um plano bidimensional. Os resultados mostraram que uso de ureia e de cloreto de potássio não teve efeito de entupimento nos emissores no período estudado, nem teve efeito de redução do $\mathrm{pH}$ do solo ou de variação do nível de salinidade. O alcance do potássio aplicado via água por gotejamento pela fonte cloreto de potássio foi de $0,40 \mathrm{~m}$ em distância horizontal do gotejador e em profundidade e a região do volume molhado de maior variação da concentração do potássio ocorreu entre o gotejador e a planta.
\end{abstract}

Palavras-chave: Condutividade elétrica, extratores, efeito.

\footnotetext{
${ }^{1}$ Eng. Agrônomo, Mestrando em Engenharia Agrícola pela Universidade Federal de Viçosa, Viçosa, Minas Gerais, Brasil, e-mail: dionei_lima12@hotmail.com

${ }^{2}$ Eng. Agrícola, Pesquisador da Empresa Brasileira de Pesquisa Agropecuária, Cruz das Almas, Bahia, Brasil, email: eugenio.coelho@embrapa.br

${ }^{3}$ Eng. Agrônomo, Mestrando em Recursos Hídricos pela Universidade Federal de Sergipe, São Cristóvão, Sergipe, Brasil, e-mail: lucasbaptistaufrb@gmail.com

${ }^{4}$ Eng $^{\mathrm{a}}$ Agrônoma, Mestranda em Engenharia Agrícola pela Universidade Federal do Recôncavo da Bahia, Cruz das Almas, Bahia, Brasil, e-mail: damibarros@ hotmail.com

${ }^{5}$ Eng. Agrônomo, Professor adjunto do curso de Engenharia Agrícola na Universidade Federal de Sergipe, São Cristóvão, Sergipe, Brasil, e-mail: rrgomesfilho@hotmail.com

${ }^{6}$ Tecnólogo em Recursos Hídricos e Irrigação, Doutor em Engenharia Agrícola pela Universidade Federal do Ceará, Fortaleza, Ceará, Brasil, e-mail: carvalho_cmc@yahoo.com.br
} 


\title{
EFFECT OF UREA AND POTASSIUM CHLORIDE BY FERTIRRIGATION IN FLOW OF THE EMITTERS AND IN CHEMICAL PARAMETERS OF THE SOIL
}

\begin{abstract}
The fertirrigation has been incorporated to production systems of various fruit trees in Brazil, resulting in greater demand for knowledge of this technology in relation to its effect on the dynamics of solutes in the soil. Given this context, this study aimed to evaluate the effects of the use of fertiliser urea and potassium chloride through irrigation water on the issue of water by issuers and on soil chemical attributes ( $\mathrm{pH}$ and electrical conductivity) in papaya crop for drip irrigation. The evaluations were conducted within an experiment outlined in randomized blocks, where the treatments consisted of five doses of $\mathrm{N}$ and five doses of $\mathrm{K}_{2} \mathrm{O}$, totaling 10 treatments. Were installed in a solution in the soil to the horizontal distances of $0.03 \mathrm{~m}, 0.20$ $\mathrm{m}, 0.40 \mathrm{~m}$ and $0.60 \mathrm{~m}$ from the dripper, the depths of $0.20 \mathrm{~m}, 0.40 \mathrm{~m}, 0.60 \mathrm{~m}$ and $0.80 \mathrm{~m}$ near the plant, in order to simulate a two-dimensional plane. The results showed that the use of urea and potassium chloride had no effect of clogging in the issuers in the period studied, nor had the effect of reducing the soil $\mathrm{pH}$ or changes in the level of salinity. The range of potassium applied via water drip irrigation by source of potassium chloride was $0.40 \mathrm{~m}$ in the horizontal distance from the dripper and in depth and the region of the volume wet with greater variation in the concentration of potassium occurred between the dripper and the plant.
\end{abstract}

Keywords: Electrical conductivity, extractors, transmitters.

\section{INTRODUÇÃO}

O Brasil é o maior é o maior produtor mundial de mamão (Carica papaya L.), com uma produção aproximadamente 1,9 milhões de toneladas/ano representando $10 \%$ da produção mundial de frutas tropicais, girando em torno de 8 milhões de toneladas, das quais $39 \%$ são produzidas na América Latina e Caribe (FAO, 2009). O fruto é cultivado em quase todo o território brasileiro, mas merecem destaque os Estados da Bahia, Espírito Santo, Ceará e Rio Grande do Norte (IBGE, 2015).

A falta ou má distribuição das chuvas nas regiões produtoras do mamoeiro torna obrigatório aplicação da irrigação de forma racional, com eficiência máxima nas lavouras comerciais dessa cultura. A irrigação, tem trazido consigo a atividade de aplicação de adubos via água, ou a fertirrigação, que vem sendo usada em ritmo crescente pelos fruticultores sem metodologia adequada, usando-se recomendações empíricas (BORGES; SILVA, 2002).

Oliveira e Caldas (2004), em pesquisa com o objetivo de determinar as doses de nitrogênio, fósforo e potássio para o mamoeiro do grupo Solo, nas condições edafoclimáticas de Cruz das Almas (BA), constataram que o uso da adubação nitrogenada e potássica proporcionou aumento de produtividade da cultura.

Neste sentido, a adubação nitrogenada e potássicos sob efeito de liberação lenta, economicamente importantes culturas, tem sido relatada na literatura científica com ênfase em estudos com grandes culturas, tais como do milho (NOELLSCH et al., 2009), além de culturas vegetais como tomate (FAN et al., 2009) e repolho (RODRIGUES et al., 2010), e espécies de frutos como pêssego (KANDIL et al., 2010), goiaba (OSMAN et al., 2009) e manga (EMAN et al., 2009). No entanto, especificamente para a cultura do mamoeiro, estudos sobre a viabilidade da utilização de fertilizantes de liberação controlada no Brasil e no mundo ainda são incipientes.

Dessa forma, há necessidade de se verificar os efeitos dessas fontes no solo de modo a obter subsídios para elaboração de critérios para uso dos mesmos em fertirrigação. O presente trabalho teve por objetivo avaliar os efeitos do uso dos fertilizantes uréia e cloreto de potássio via água de irrigação na emissão de 

DOS EMISSORES E EM PARÂMETROS QUÍMICOS DO SOLO

água pelos emissores e nos atributos químicos do solo ( $\mathrm{pH}$ e condutividade elétrica) na cultura do mamoeiro, cultivar Sunrise Solo.

\section{MATERIAL E MÉTODOS}

O presente trabalho foi conduzido
no Laboratório
Fertirrigação da Embrapa Mandioca e Fruticultura Tropical, em Cruz das Almas $\left(12^{\circ}\right.$ $48^{\prime} \mathrm{S} ; 39^{\circ} 06^{\prime} \mathrm{W}$ e $\left.225 \mathrm{~m}\right)$, de acordo as premissas da Embrapa (2006) o solo foi classificado como Franco-argilo-arenoso. Usou-se um experimento já instalado num delineamento experimental em blocos ao acaso, com quatro repetições, onde os tratamentos seguiram uma matriz PlanPuebla III, modificado por Leite (1984), correspondendo a um fatorial $2 \mathrm{k}+2 \mathrm{k}+1+1$ (sendo $\mathrm{k}$ o número de fatores estudados de dois fatores, sendo cinco doses de $\mathrm{N}$ e cinco doses de $\mathrm{K}_{2} \mathrm{O}$, formando 10 tratamentos pela interação das doses dos dois nutrientes (Tabela 1).

Tabela 1. Interação doses de $\mathrm{N}$ e doses de $\mathrm{K}_{2} \mathrm{O}$ para aplicação via água de irrigação no mamoeiro.

\begin{tabular}{ccccccccccc}
\hline Tratamentos & T1 & T2 & T3 & T4 & T5 & T6 & T7 & T8 & T9 & T10 \\
\hline Doses de N $\left(\mathrm{kg} \mathrm{ha}^{-1}\right)$ & 210 & 210 & 490 & 490 & 35 & 665 & 210 & 490 & 350 & 35 \\
Doses de K $\left(\mathrm{kg} \mathrm{ha}^{-1}\right)$ & 210 & 490 & 210 & 490 & 210 & 490 & 35 & 665 & 350 & 35 \\
\hline
\end{tabular}

A avalição da CE e do potássio da solução do solo em função das distâncias dos gotejadores, em diferentes períodos relativos ao evento da fertirrigação foi executada utilizando-se dos 10 tratamentos, apenas o T8, T9 e o T10, os quais consistiam as doses mais recomendadas para esta cultura, de acordo a estudos prévios realizados na área do presente trabalho.

Foram feitas fertirrigações semanais, em que as soluções de fertilizantes foram preparadas usando recomendação de Vitti et al (1994), considerando a concentração na saída dos emissores de $1300 \mathrm{mg} \mathrm{L}^{-1}$, valor superior ao sugerido por Pizarro (1987). Nos tratamentos selecionados foram instalados extratores de solução no solo às distâncias horizontais de $0,03 \mathrm{~m}, 0,20 \mathrm{~m}, 0,40 \mathrm{~m} \mathrm{e}$ $0,60 \mathrm{~m}$ do gotejador, às profundidades de $0,20 \mathrm{~m}, 0,40 \mathrm{~m}, 0,60 \mathrm{~m}$ e $0,80 \mathrm{~m}$ entre a planta e o gotejador, em linhas imaginarias radiais ao gotejador, de forma a simular um plano bidimensional. As amostras de solução do solo em cada posição foram extraídas entre duas fertirrigações, em três tomadas de dados. As amostras de solução de solo foram levadas para o laboratório para avaliação da condutividade elétrica (CE), ode um condutivimetro e do teor de potássio, determinado por fotometria de chama (MACIEL, 1998).

A avalição do $\mathrm{pH}$ e da $\mathrm{CE}$ do solo ao longo do tempo a $0,40 \mathrm{~m}$ de profundidade do solo nos diferentes tratamentos também foi feita. As soluções de fertilizantes foram preparadas usando recomendação de Vitti et al (1994), considerando a concentração na saída dos emissores de $1300 \mathrm{mg} \mathrm{L}^{-1}$, acima do valor sugerido por Pizarro (1987). Foi feito, aos 150, 510,570 e 720 dias após o plantio, uma coleta de vazão em dois gotejadores de cada parcela experimental, ou cada tratamento nos quatro blocos, com uso de becker e cronômetro, sendo que se determinou a condutividade elétrica da água coletada, usando-se de um condutivimetro portátil. Foram feitas coletas de solução de solo em extratores de solução instalados junto a planta e a distância de $0,40 \mathrm{~m}$ do gotejador, a profundidade de $0,40 \mathrm{~m}$ para todos os tratamentos aos 330, 360, 390, 590, 620, 653, 683, 713, 743 e 776 dias após o plantio.

As amostras de solução de solo foram levadas para o laboratório para avaliação de $\mathrm{pH}$ e de condutividade elétrica. Foi determinado o coeficiente de uniformidade de emissão para cada coleta de vazão e para cada tratamento. Os dados da condutividade elétrica obtidos durante a coleta da vazão foram avaliados em termos de uniformidade de distribuição por meio do 
coeficiente de uniformidade de Christiansen. Os dados de condutividade elétrica e $\mathrm{pH}$ foram avaliados ao longo de 776 dias após plantio.

\section{RESULTADOS E DISCUSSÃO}

De acordo com a Tabela 2, pode-se verificar que os coeficientes de uniformidade de Christiansen (CUC) foram superiores a $85 \%$ para todos os tratamentos, tendo sido superior a $90 \%$ em seis dos dez tratamentos, demonstrando que o sistema apresenta uma classificação excelente de uniformidade, de acordo com a identificação proposta por Mantovani (2001). Fato que corrobora com reportado por Cunha et al. (2015), no estudo da uniformidade de aplicação de fertilizantes sob um sistema de gotejamento subsuperficial, aos autores concluíram que o CUC também apresentou uma excelente classificação.

Segundo Camargo (2010), quando o fertilizante é colocado de molho em água por algumas horas antes da aplicação facilita a dissolução e redução de entupimentos dos emissores do sistema de irrigação, em consequência disso, uma melhor uniformidade de distribuição da solução nutritiva.

Tabela 2. Coeficientes de uniformidade de Christiansen (CUC) e médias das condutividades elétricas na saída dos gotejadores para cada tratamento.

\begin{tabular}{|c|c|c|c|c|}
\hline Tratamento & $\begin{array}{c}\text { Doses de N } \\
\left(\mathrm{kg} \mathrm{ha}^{-1}\right)\end{array}$ & $\begin{array}{c}\text { Doses de K } \\
\left(\mathrm{kg} \mathrm{ha}^{-1}\right)\end{array}$ & 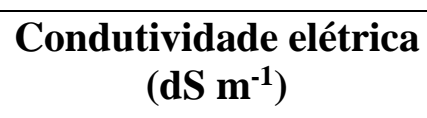 & $\begin{array}{r}\text { CUC } \\
(\%)\end{array}$ \\
\hline 1 & 210 & 210 & 1,455 & 97,9 \\
\hline 2 & 210 & 490 & 2,015 & 85,1 \\
\hline 3 & 490 & 210 & 0,644 & 89,4 \\
\hline 4 & 490 & 490 & 0,814 & 92,4 \\
\hline 5 & 35 & 210 & 0,513 & 86,9 \\
\hline 6 & 665 & 490 & 0,705 & 95,0 \\
\hline 7 & 210 & 35 & 0,636 & 87,6 \\
\hline 8 & 490 & 665 & 1,629 & 95,6 \\
\hline 9 & 350 & 350 & 1,445 & 98,9 \\
\hline 10 & 35 & 35 & 0,432 & 94,8 \\
\hline
\end{tabular}

As diferenças nos valores das médias são devidas às diferenças entre os tratamentos $\mathrm{e}$ a composição dos níveis de nutrientes, representados pelas suas respectivas fontes de uréia de índice salino de 1,7 e cloreto de potássio de índice salino de 1,98.

Não houve tendência de redução da vazão com o tempo para o mesmo tratamento e, apesar da vazão por tratamento ser média dos gotejadores de quatro parcelas, os coeficientes de uniformidade de emissão mostram a uniformidade dos valores de vazão dentro do mesmo tratamento. Esses resultados mostram que não houve efeito de obstrução dos gotejadores pela sedimentação de sais nos emissores no período de 720 dias do plantio. Isso mostra que as concentrações dos nutrientes nas saídas dos emissores utilizada nos cálculos, apesar de exceder aos valores sugeridos por Pizarro (1987) não ocasionou problemas de sedimentação de sais, o que mostra que as concentrações na saída dos emissores podem ser superiores a $700 \mathrm{mg} \mathrm{L}^{-1}$ (Tabela

Tabela 3. Vazão média $\left(\mathrm{L} \mathrm{h}^{-1}\right)$ e uniformidade de emissão (\%) referente aos gotejadores nos tratamentos de doses de nitrogênio e de potássio durante as fertirrigações.

\begin{tabular}{ccccc}
\hline Tratamento & \multicolumn{4}{c}{ Dias após o plantio } \\
\hline & 150 & 510 & 570 & 720 \\
\hline 1 & $4,02 / 97,0$ & $4,1 / 96,3$ & $4,3 / 91,2$ & $4,1 / 65,2$
\end{tabular}




\begin{tabular}{ccccc}
2 & $4,4 / 94,9$ & $4,2 / 98,9$ & $4,5 / 93,3$ & $4,8 / 79,5$ \\
3 & $4,4 / 99,7$ & $4,5 / 93,0$ & $4,6 / 90,3$ & $4,2 / 91,8$ \\
4 & $4,4 / 94,5$ & $4,0 / 96,3$ & $4,3 / 96,5$ & $4,6 / 89,3$ \\
5 & $4,4 / 94,3$ & $4,6 / 90,2$ & $4,3 / 96,5$ & $4,2 / 92,1$ \\
6 & $4,3 / 90,3$ & $4,6 / 84,9$ & $4,2 / 92,8$ & $4,3 / 95,8$ \\
7 & $4,3 / 97,5$ & $4,5 / 93,6$ & $4,8 / 93,7$ & $4,7 / 94,8$ \\
8 & $4,2 / 97,5$ & $4,3 / 91,2$ & $4,2 / 100$ & $4,4 / 94,2$ \\
9 & $4,2 / 97,8$ & $4,2 / 99,3$ & $4,3 / 96,5$ & $4,4 / 86,2$ \\
10 & $4,0 / 92,9$ & $4,3 / 96,5$ & $4,1 / 94,5$ & $4,5 / 91,4$ \\
\hline
\end{tabular}

Observa-se que valores em cada distância são condizentes com os tratamentos, isto é, os maiores correspondem ao tratamento T8, seguido pelo tratamento T9 e T10. Exceto para o tratamento T8, observa-se uma tendência de aumento da CE a 0,40 m do gotejador, que corresponde à posição próxima da planta entre dois gotejadores. A distribuição em profundidade não mostrou tendência de maior concentração de sais a qualquer profundidade para os tratamentos T9 e T10, mas houve um ligeiro acumulo a 0,60 e $0,80 \mathrm{~m}$, para o tratamento T8 (Figura 1). Verificou-se que após a fertirrigação (Tabela 2), ocorre um aumento absoluto na concentração dos solutos até a distância de $0,40 \mathrm{~m}$, tendo-se observado redução da $\mathrm{CE}$ com o tempo mais pronunciada até o $7^{\circ}$ dias após o plantio (DAP) a 0,40 m do emissor, o que coincide com o eixo da planta. Os maiores valores de $\mathrm{CE}$ encontram-se entre $0,40 \mathrm{~m}$ e $0,60 \mathrm{~m}$ do gotejador, que corresponde a região intermediaria entre dois emissores, coincidindo com o eixo da planta.

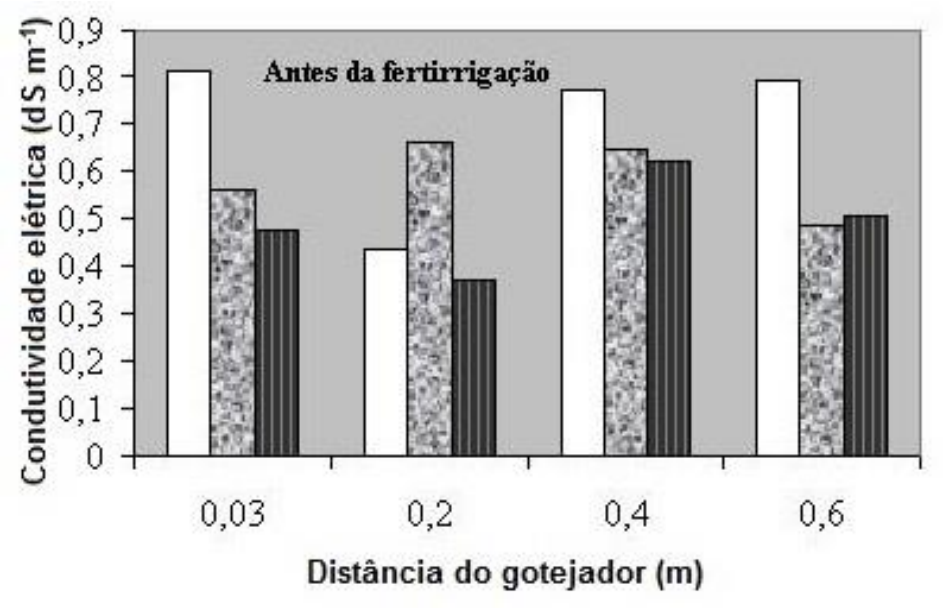

$\square \mathrm{T} 8 \mathrm{~T} 9 \mathrm{\square} 10$

Figura 1. Condutividade elétrica média de diferentes profundidades, a diferentes distâncias horizontais do gotejador antes da fertirrigação. 


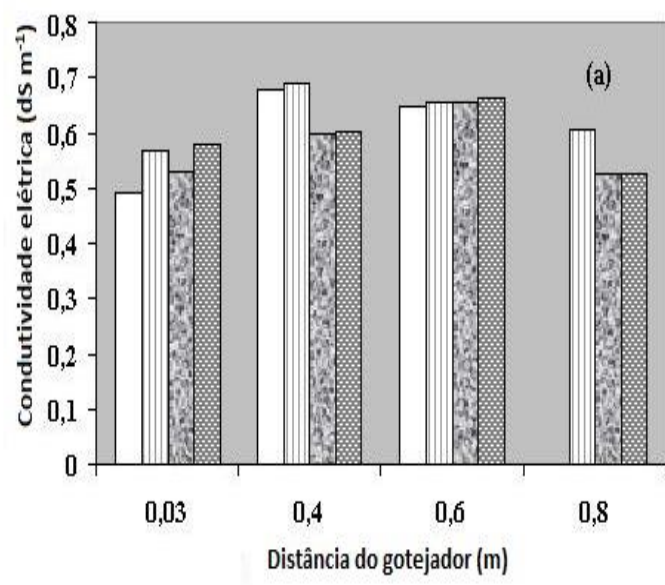

$\square 0 \square 1$ dia $\square 6$ dias 07 dias

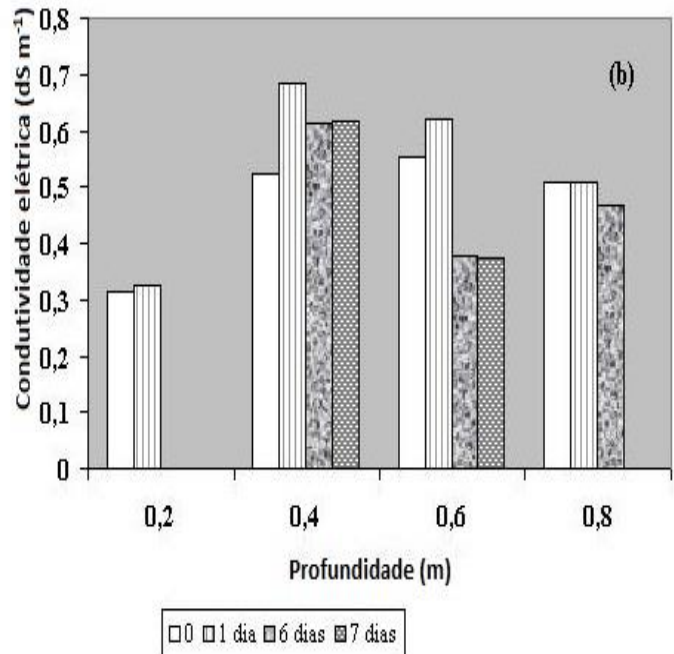

Figura 2. Condutividade elétrica da solução do solo a diferentes distâncias do gotejador (a), em diferentes períodos relativos ao evento da fertirrigação (b).

A Figura 3 mostra a distribuição de potássio medida a diferentes distâncias do gotejador e a diferentes profundidades do solo. Nota-se que incremento na concentração de potássio foi mais pronunciado até a distância do gotejador de $0,40 \mathrm{~m}$ e a profundidade de $0,40 \mathrm{~m}$. Os resultados indicam que o alcance do potássio aplicado por gotejamento pelo cloreto de potássio foi de 0,40 m em distância horizontal do gotejador e em profundidade, o que foi concordante com Maciel (1998).

Laurindo et al. (2010) estudando o padrão de distribuição de $\mathrm{K}^{+}, \mathrm{Ca}^{++}, \mathrm{Mg}^{++}$e $\mathrm{P}$ no

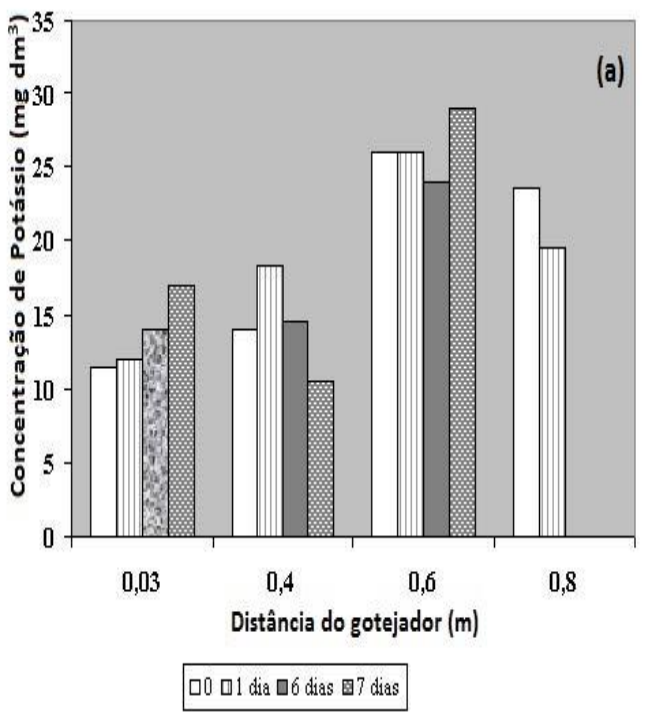

solo de um pomar de citros em função da fertirrigação reportaram que, os teores de potássio no solo, quando a fertirrigação com este elemento é feita por gotejamento, diminuem radialmente com o aumento da distância horizontal do ponto de aplicação, na direção ortogonal à linha de plantas, até a profundidade de $60 \mathrm{~cm}$. Esse comportamento justifica-se à medida que a fertirrigação tornase mais eficiente com o aumento da disponibilidade de água no solo, principalmente com relação aos nutrientes com elevada solubilidade, como o nitrogênio e o potássio (Dalri et al., 2008)

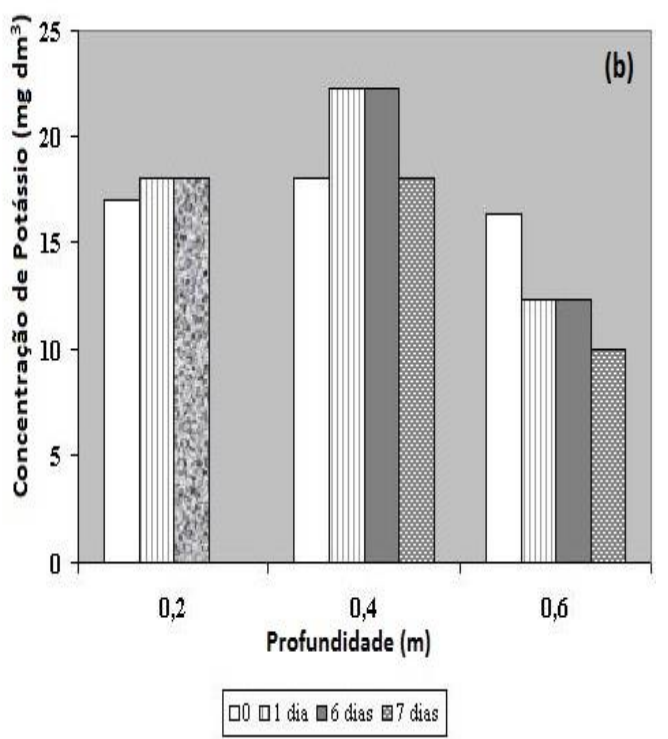

Figura 3. Concentração de potássio da solução do solo a diferentes distâncias do gotejador (a), em diferentes períodos relativos ao evento da fertirrigação (b). 

DOS EMISSORES E EM PARÂMETROS QUÍMICOS DO SOLO

A Figura 4 ilustra o comportamento do pH do solo a $0,40 \mathrm{~m}$ durante 776 dias após o plantio, sendo que em nenhum dos tratamentos há uma tendência explicita de redução de $\mathrm{pH}$, mas uma tendência de estabilização do mesmo. Tendo em vista o período superior a dois anos, nota-se que o uso da uréia não afetou o esse parâmetro no solo, não concordando, portanto com Costa et al. (2008) estudando doses e fontes de nitrogênio em pastagem e as alterações nas características químicas do solo, os autores concluíram que a uréia pode provocar redução no $\mathrm{pH}$ do solo até $0,40 \mathrm{~m}$ de profundidade. Os mesmos autores ainda afirmaram que a acidificação provocada por adubos nitrogenados não se restringe apenas à camada superficial, mas afeta também a subsuperfície solo.

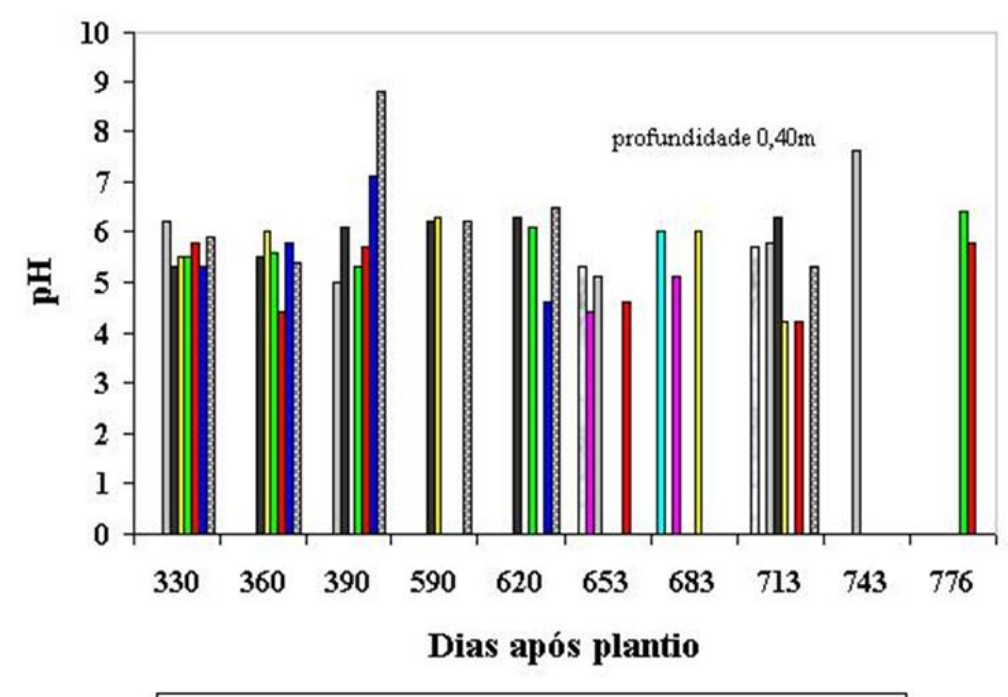

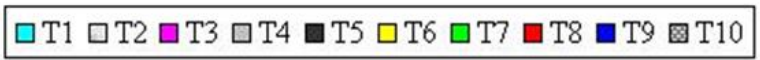

Figura 4. Variação do $\mathrm{pH}$ ao longo do tempo a $0,40 \mathrm{~m}$ de profundidade do solo nos diferentes tratamentos de aplicação de doses de nitrogênio e de potássio via fertirrigação.

Em relação ao comportamento da condutividade elétrica no solo sob os diferentes tratamentos, nota-se que os tratamentos de maior concentração de nitrogênio e de potássio resultaram em maior condutividade elétrica no solo, tais como T8, T6 e T4, o que era esperado. Não houve, entretanto para um mesmo tratamento tendência de elevação da condutividade elétrica com o tempo, sendo que os valores observados são condizentes com a tolerância do mamoeiro, estando em média abaixo de $1 \mathrm{dS} \mathrm{m}^{-1}$ para todos os tratamentos, inclusive os de maior concentração dos nutrientes 


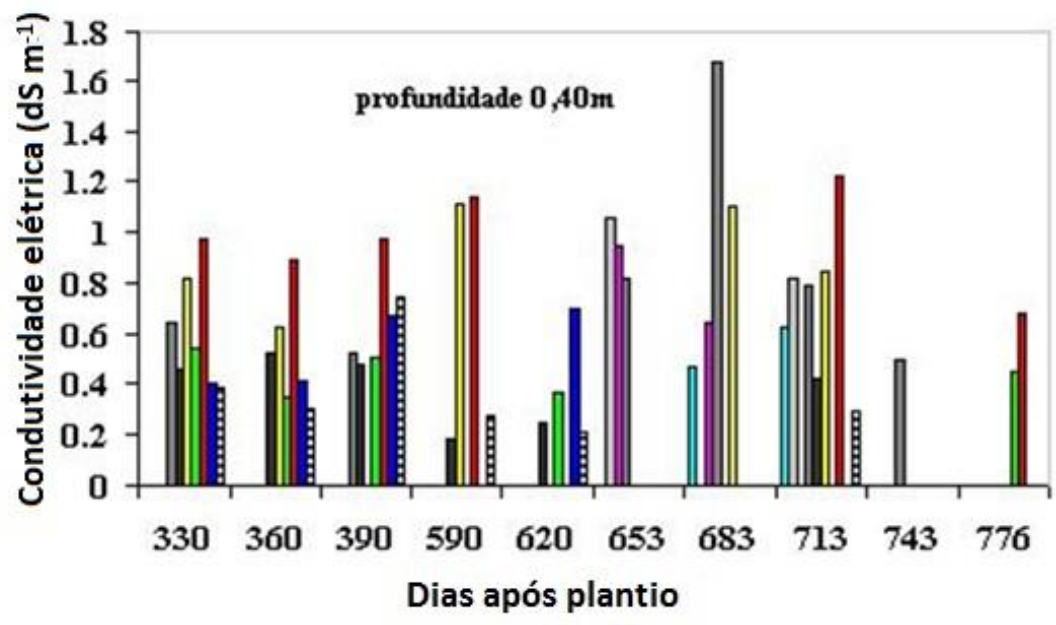

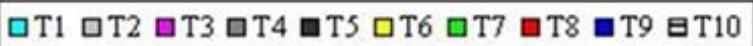

Figura 5. Variação da condutividade elétrica ao longo do tempo a $0,40 \mathrm{~m}$ de profundidade do solo nos diferentes tratamentos de aplicação de doses de nitrogênio e de potássio via fertirrigação.

\section{CONCLUSÕES}

O alcance do potássio aplicado por gotejamento pelo cloreto de potássio foi de $0,40 \mathrm{~m}$ em distância horizontal do gotejador e em profundidade.

A região do volume molhado onde possivelmente maior atividade do sistema radicular por absorção do potássio ocorreu entre o gotejador e a planta com distância 0,40 $\mathrm{m}$ e profundidade de $0,40 \mathrm{~m}$.

A fertirrigação pelo uso de uréia e de cloreto de potássio não ocasionou o entupimento nos emissores no período estudado, nem teve efeito de redução do $\mathrm{pH}$ do solo ou de variação do nível de salinidade.

\section{REFERÊNCIAS BIBLIOGRÁFICAS}

BORGES, A. L.; SILVA, D. J. Fertirrigação em fruteiras tropicais. 1. ed. Cruz das Almas: Embrapa Mandioca e Fruticultura Tropical, 2002. $137 \mathrm{p}$.

CAMARGO, D. C. Uniformidade de distribuição de potássio utilizando diferentes fontes de e concentrações na calda de fertirrigação em condições de campo. 2010. 66f. Dissertação (Mestrado em Engenharia Agrícola) - Universidade Federal do Ceará, Fortaleza.
COSTA, K. A. P.; FAQUIN, V.; OLIVEIRA, I. P.; RODRIGUES, C.; SEVERIANO, E. C. Doses e fontes de nitrogênio em pastagem de capimmarandui - alterações nas características químicas do solo. Revista Brasileira de Ciência do Solo, v. 32, n. 2, p. 1591-1599, 2008.

CUNHA, F. N.; SILVA, N. F.; TEIXEIRA, M. B.; CARVALHO, J. J.; MOURA, L. M. de F. MELO, S. R. P. de. Uniformidade de aplicação de fertilizantes sob um sistema de gotejamento subsuperficial. Revista Brasileira de Agricultura Irrigada, v. 8, n. 5, p. 391-402, 2014.

DALRI, A. B.; CRUZ, R. L.; GARCIA, C. J. B.; DUENHAS, L. H. Irrigação por gotejamento subsuperficial na produção $\mathrm{e}$ qualidade de cana-de-açúcar. Irriga, v. 13, n. 1, p.1-11, 2008.

EMAN, E.; EL-MONEM, A. A. A.; SALEH, M. M. S.; MOSTAFA, E. A. M. Effect of ureaformaldehyde as a slow release nitrogen fertilizer on productivity of mango trees. Green Farming, v. 2, n. 9, p. 592-595, 2009.

EMBRAPA - Empresa Brasileira de Pesquisa Agropecuária. Centro Nacional de Pesquisa de 

DOS EMISSORES E EM PARÂMETROS QUÍMICOS DO SOLO

Solos. Sistema brasileiro de classificação de solos. Rio de Janeiro, 2006.

FAN, X. H.; LI, Y. C. Effects of slow-release fertilizers on tomato growth and nitrogen leaching. Communications in Soil Science and Plant Analysis, v. 40, n. 22, p. 3452-3468, 2009.

FAO. Perspectivas de la agricultura y del desarrollo rural en las Américas: uma mirada hacia América Latina y Caribe. FAO/IICA/CEPAL, 2009. Disponível em: < http://www.iica.int/es/Esp/organizacion/LTGC/ modernizacion/Publica\%20ciones \%20de\%20M odernizacin\%20Institucional/B1560E.pdf>.

Acesso em: $<20$ jun. 2012.

Instituto Brasileiro de Geografia e Estatística IBGE. Sistema IBGE de Recuperação Automática - IBGE. (2015). Disponível em: <http://www.sidra.ibge.gov.br/bda/acervo/acer vo9. $a s p ? e=c \& p=P A \& z=t \& o=11>$. Acesso em: 13 ago. 2015.

KANDIL, E. A.; FAWZI, M. I. F. M.; SHAHIN, F. M. The effect of some slow release nitrogen fertilizers on growth, nutrient status and fruiting of "Mit Ghamr" peach trees. Journal of American Science, v. 6, n. 12, p. 195-201, 2010.

LAURINDO, V. T.; SILVA, G. O.; PAVANI, L. C.; QUAGGIO, J. A. Padrão de distribuição de $\mathrm{K}^{+}, \mathrm{Ca}^{++}, \mathrm{Mg}^{++}$e $\mathrm{P}$ no solo de um pomar de citros em função da fertirrigação. Engenharia. Agrícola, v. 30, n. 5, p. 909-921, 2010.

LEITE, R. A. Uso de matrizes experimentais e de modelos estatísticos no estudo de equilíbrio fósforo-enxofre na cultura da soja em amostras de dois Latossolos de Minas Gerais. 1984. 87 f. Dissertação (Mestrado em Ciência do Solo) - Universidade Federal de Viçosa, Viçosa.

MACIEL, J. L. Distribuição do fósforo e do potássio no perfil do solo aplicado via água de irrigação por gotejamento subsuperficial. 1998. 59f. Dissertação (Mestrado em Engenharia Agrícola) - Universidade Federal do Ceará, Fortaleza.

MANTOVANI, E. C. AVALIA Manual do usuário. 1. ed. Viçosa: DEA/UFV PNP\&D/café/EMBRAPA. 2002. 100 p.

NOELLSCH, A. J.; MOTAVALLI, P. P.; NELSON, K. A.; KITCHEN, N. R. Corn response to conventional and slow-release nitrogen fertilizers across a claypan landscape. Agronomy Journal, v. 101, n. 3, p. 607-614, 2009.

OLIVEIRA, A. M. G.; CALDAS, R. C. Produção do mamoeiro em função de adubação com nitrogênio, fósforo e potássio. Revista Brasileira Engenharia Agrícola Ambiental, v. 26, n. 1, p. 160-163, 2004.

OSMAN, S. M.; EL-RAHMAN, A. E. M. Effect of slow release nitrogen fertilization on growth and fruiting of guava under Mid Sinai conditions. Australian Journal of Basic and Applied Sciences, v. 3, n. 4, p. 4366-4375, 2009.

RODRIGUES, M. A.; SANTOS, H.; RUIVO, S.; ARROBAS, M. Slow-release N fertilizers are not an alternative to urea for fertilization of autumn-grown tall cabbage. European Journal of Agronomy, v. 32, n. 2, p. 137-143, 2010 .

PIZARRO, F. Riegos localizados de alta frequência. 1. ed. Madrid: Ediciones Mundi Prensa, 1987. 514 p.

VITTI, G. C.; BOARETTO, A. E.; A. E, PENTEADO, S. R. Ferlizantes e fertirrigação. In: VITTI, G C.; BOARETTO, A. Fertilizantes fuidos. 1. ed. Piracicaba: Potatos, 1994. cap. 7, p. 262-281. 